\title{
Ciclismo saludable bajo techo
}

\author{
Health Indoor Cycling $(\mathrm{HIC})^{*}$
}

\author{
Édgar A. Rodriguez Manchola** \\ Diego Ermith Corredor López** \\ Angélica Avendaño Valencia* \\ Martín Emilio Henao Vásquez***
}

\section{Resumen}

Palabras clave: Ciclismo, entrenamiento, salud, condición física, prevención, cardiovascular, aeróbico, spinning.

Con la aprobación de la Ley 729 de 2001, por medio de la cual se crean los Centros de Acondicionamiento y Preparación Física en Colombia, surge la necesidad de capacitarse en áreas relacionadas con la salud. En el programa HIC, los entrenadores en proceso de capacitación podrán profundizar en la morfofisiología y la biomecánica aplicadas al HIC, a fin de prevenir lesiones físicas y poner en práctica los diferentes métodos de entrenamiento de la resistencia dentro de las diferentes zonas energéticas a los entrenados. Éstos últimos deberán ser valorados previamente, con su respectiva prueba de esfuerzo, para que el entrenador controle, prescriba y dosifique la carga individual de trabajo y asi poder cumplir con los objetivos del entrenado, y que a su vez, su trabajo cardiovascular esté motivado y enmarcado en un concepto virtual de lo que sería un trabajo en terreno real.

Este programa es ideal para comenzar el entrenamiento cardiovascular y para terapias de rehabilitación. Sin embargo, existen algunas desventajas con la bicicleta estática en los centros de ejercicio:

- Dificultad para mantener intensidades apropiadas con el fin de lograr efectos óptimos de entrenamiento, por lo cual se recomienda el uso de monitores de la frecuencia cardiaca o por lo menos su monitoreo palpando las pulsaciones con el dedo índice y medio.

- Estrés ortopédico, en particular de la zona lumbar, el cuello y los hombros por mantener posiciones estáticas por largos periodos.

- Dificultad para mantener el interés y la motivación de los participantes

El programa de entrenamiento de Health Indoor Cycling prepara al entrenador para resolver este tipo de problemas. Está enfocado y comprometido en ayudar a los alumnos a alcanzar sus objetivos de preparación física. También incorpora métodos de enseñanza y técnicas de instrucción para minimizar el estrés ortopédico e incrementar la comodidad al montar en bicicleta. Reduce el peso corporal del usuario, y puesto que la carga esta dada en rozamiento con una buena biomecánica reduce la posibilidad de lesiones.

Además, los entrenadores se preparan para aumentar su liderazgo y aptitudes motivacionales en clase.

\section{Abstract}

In 2001 the Colombian Congress passed the Act 729 of 2001, which sets the procedure required for opening the Fitness and Physical Preparation Centers. This brought about the necessity to be qualified for health related areas. In the HIC program, trainers-to-be study in depth the applications of morphophysiology and biomechanics to the HIC, in order to prevent lesions and implement the different physical resistance training methods on the energetic zones of the trainees. These should be previously assessed through different tests, including a stress test, so that the trainer might be able to control and gradually prescribe the right amount of individual exercise. This will lead trainees to attain the set goals, and motivate them to perform the cardiovascular activity.

Although this program is excellent to start the cardiovascular training and for physical therapy rehabilitation, there are some disadvantages associated to the use of static bicycle in the sports centers, such as:

- Difficulty to keep appropriate exercise intensities to achieve optimal training results. For this reason, it is recommended to use heart rate monitors, or, at least, to monitor it by palpating the beats using the index and middle fingers.

- Orthopaedic stress, particularly on the lumbar region, neck and shoulders, derived from keeping static positions for long periods of time.

- Difficulty to maintain the participants' interest and motivation.

The HIC program prepares trainers to solve the problems mentioned above. It focuses on and is committed to helping students attain their physical preparation goals. It also combines teaching methods and instruction techniques to minimize the orthopaedic stress and discomfort when bike riding, and reduces the user's body weight. Because the load is applied in friction with a good biomechanics, it reduces the risk of lesions.

Additionally, the trainers are taught to increase their leadership and motivational skills in class.

Key words: $\quad$ Cycling, training, health, fitness, prevention, cardiovascular, aerobic, spinning.

Fecha de recepción: 24 de octubre de 2006

Fecha de aceptación: 16 de noviembre de 2006

* Derechos de autor: Diego E. Corredor López y Édgar Alberto Rodríguez Manchola. Certificado de registro de soporte lógicor libro 13, tomo 11, partida 404. Fecha de registro: 12 de abril de 2004. Ministerio del Interior y de Justicia; Dirección Nacional de Derechos de Autor.

** Autores.

${ }^{* * *}$ Asesor metodológico y didáctico. 


\section{Introducción}

El ciclismo saludable bajo techo (Health indoor cycling) es un plan de trabajo enfocado en una nueva forma de desarrollar un entrenamiento personalizado y saludable sustentado en bases científicas y laboratorios efectuados gó Édgar Alberto Rodríguez Manchola técnico laboral entrenamiento deportivo y actualmente estudiande Licenciatura en Educación Física de la Universilad Pedagógica Nacional. Ha contado con la asesoría tel Licenciado en Educación Física de la Universidad Pedagógica Nacional y Especialista en Altos Estudios del Deporte, Diego Ermith Corredor López; Angélica Avendaño Valencia, Administradora de Empresas de Universidad Nacional de Colombia; Martín Emilio Henao Vásquez, Licenciado en Educación Física y Especialista en Pedagogía del Entrenamiento Deportivo, le la Universidad Pedagógica Nacional, y postulante a Magíster en Educación, de la Universidad Pedagógica Nacional. Sus valiosos aportes desde la parte teórica y gráctica hicieron posible la realización de este texto. gualmente, el Centro de Capacitación y Entrenamiento Técnico, CCET, fue un soporte que facilitó herramienas de carácter humano, tecnológico y físico por medio e sus instalaciones.

\section{Entrenamiento funcional y beneficios en la prevención de lesiones}

El programa Health Indoor Cycling está diseñado para enseñar a los alumnos técnicas efectivas de ciclismo y aumenta la diversión en este tipo de actividades de sain, a fin de prepararlos en actividades al aire libre con ondiciones variables del camino y para prevenir lesiohes y estrés biomecánico innecesarios en ambas opciones: en un salón o en carretera.

La prevención de lesiones por sobreuso es vital para Al éxito de cualquier programa de entrenamiento. Hasta ahora, una gran desventaja del ciclismo como forma de acondicionamiento aeróbico ha sido la dificultad para minimizar la fatiga muscular y articular localizada al grincipio del entrenamiento, teniendo en cuenta que a la vez debe minimizarla o eliminarla por una duración suficiente, necesaria para el efecto del trabajo aeróbico.

Los entrenadores deben estar conscientes del estrés articular y muscular de ciclismo, debido a que es muy repetitivo como movimiento y totalmente específico en el plano muscular. La carga localizada en los músculos tel tren inferior y la incomodidad propia de las posiciones estáticas en el tren superior y el torso causan una molestia inicial que debe ser disminuida, de modo espe- cial si los alumnos son nuevos y se les quiere involucrar en este tipo de ejercicio en forma efectiva.

El ciclismo bajo techo ofrece un programa serio y confiable ya que va mucho mas allá del ciclismo normal, tiene en cuenta la parte funcional del torso y el tren superior en posiciones estáticas y sentado, mejora la postura y la resistencia para actividades como el ciclismo y para cualquier otra actividad en la vida diaria que requiera estar sentado. Además, está diseñado para disminuir y eliminar la fatiga en la zona dorsolumbar, en la parte alta de la espalda, en la cintura escapular, en el cuello y en los hombros.

\section{Beneficios de liderazgo y motivación}

Otra de las desventajas de la bicicleta estática normal en el gimnasio ha sido mantener la motivación durante una actividad que es tan repetitiva durante el tiempo adecuado para mejorar la condición aeróbica. Este entrenamiento incorpora las técnicas necesarias desde el punto de vista psicológico para ayudar a conseguir los objetivos del entrenamiento, además de los distintos diseños de clases para hacer cada clase diferente, y como complemento el estímulo que trae la música, el cual debe ser bien manejado por el entrenador para evitar la euforia excesiva.

\section{Ciencias aplicadas al ciclismo bajo techo}

La mayor parte de las investigaciones acerca del ciclismo a través de los años ha estado enfocada en analizar los efectos fisiológicos, aunque recientemente algunos investigadores han revisado los aspectos biomecánicos del ciclismo, y otros, lo concerniente a la parte psicológica. En este programa de entrenamiento están integrados cuatro elementos: el fisiológico (López y Fernández, 1995: 127-137), el biomecánico (Páez, 2004), análisis de la biomecánica aplicada al ciclismo bajo techo realizado en los laboratorios del CIREC, por el ingeniero Francesco Páez; el psicológico (Puche, 2004); y el entrenamiento de la resistencia (Fritz, 1991, cap 6).

\section{Fisiología del esfuerzo en ciclismo}

Muchas investigaciones se han llevado a cabo en los últimos años para determinar los parámetros apropiados de entrenamiento para el acondicionamiento aeróbico. Estos parámetros, organizados y recomendados por el Colegio Americano de Medicina Deportiva, reconocen el ciclismo como trabajo aeróbico, al igual que otras actividades, como correr, trotar y hacer ejercicios de danza aeróbica, teniendo en cuenta que las tres últimas generan impacto. 
El reto que representa para el ciclismo la comparación con las otras opciones es lograr el mismo entrenamiento y que pueda ser monitoreado claramente.

En una actividad tan específica para los músculos del tren inferior como el ciclismo, la resistencia muscular se desarrolla de usualmente antes que pueda ser alcanzado un verdadero efecto de entrenamiento aeróbico, entonces debe entenderse de manera correcta la diferencia entre el concepto de fatiga muscular localizada y resistencia y el concepto de fatiga sistemática y resistencia cardiovascular.

Los entrenadores de este tipo de actividad en bicicleta deben conocer con anterioridad los principios del trabajo aeróbico, y su incidencia cardiovascular para que el HIC sea exitoso. El objetivo del Programa en el área fisiológica es ofrecer unas condiciones en las cuales el participante pueda alcanzar beneficios cardiovasculares.

\section{Misión}

Utilizar el método del Health Indoor Cycling para aplicar y aprovechar todas las técnicas del entrenamiento de la resistencia con respecto a los usuarios del ciclismo bajo techo.

\section{Visión}

Lograr que quien practique el ciclismo bajo techo alcance sus objetivos específicos deseados en cuanto a salud, estética y rendimiento, mediante la aplicación del método Health Indoor Cycling.

\section{Objetivo}

Capacitar a los instructores de ciclismo bajo techo y a las personas interesadas en esta modalidad, en las técnicas utilizadas en el Health Indoor Cycling con bases sustentadas en morfofisiología, biomecánica y entrenamiento de la resistencia, como también capacitar a los instructores para que lo enfoquen y lo apliquen en los diferentes tipos de poblaciones.

\section{Historia del ciclismo bajo techo'}

El ciclismo bajo techo surge inicialmente en Estados Unidos, y es desarrollado en 1987 por el ciclista norteamericano Johnny Goldberg (Johnny “G”). La bicicleta utilizada es la denominada por su creador como "Spin-

1 José López Chicharro y Almudena Fernández Vaquero. Fisiología del ejercicio. Madrid: Editorial Médica Panamericana, 1995. ner". Lo promovía una empresa de educación llamada Mad Dogg Athletics, Inc. Su carrera como ciclista lo lleva a participar varias veces en el Race Across America, una carrera que cubre $6.500 \mathrm{~km}$. El Spinning no sólo se ocupa de la parte física, sino también de la parte mental, ya que las diferentes rutinas ayudan a liberar el estrés. Johnny G comienza a enseñar el Spinning en el garaje de su casa y con el paso del tiempo su popularidad aumenta hasta llegar a oídos de los dueños de los grandes gimnasios, donde después se implementa. Johnny G combina un poco de yoga, otro poco del Tour de France y un conjunto detallado de movimientos combinados con un entrenamiento de la frecuencia cardiaca. El nombre Spinning y el nombre Schwinn son nombres patentados ${ }^{\circ}$. El ciclismo bajo techo pasa por un proceso de investigación que dura 60 años para llegar a convertirse en deporte.

\section{Qué es el Spinning ${ }^{\circledast}$}

Spinning ${ }^{\circledR}$, que significa girar, es montar en bicicletas estáticas bajo techo, tratando de desarrollar las técnicas del ciclismo de ruta y simulando los tipos de terreno existentes, con el incentivo adicional de un instructor especializado en la materia y la música. Johnny Goldberg pone en práctica los conocimientos adquiridos en sus años como ciclista profesional y cinturón negro de karate, junto con sus estudios de la filosofía Zen, para crear un ejercicio de bajo impacto pero muy efectivo, por lo cual incluye dentro en su método Spinning algunas ideas como la relajación, la visualización y técnicas de respiración.

\section{Para qué sirve el ciclismo bajo techo}

El ciclismo bajo techo, entre sus principales objetivos, busca:

- El fortalecimiento cardiaco o aumento de la fuerza del corazón, mediante el mejoramiento en la disminución de las pulsaciones (frecuencia cardiaca), durante el proceso de recuperación luego de realizar un esfuerzo.

- Aumento del volumen cardiaco o disminución de la frecuencia cardiaca en reposo.

- Aumento del número de vasos capilares.

- Procesos de betaoxidación o mejoramiento del metabolismo, para obtener una mayor efectividad en el proceso de oxidación de calorías de lípidos.

- Alternativa de entrenamiento para los deportistas. 
Acondicionamiento físico en personas sedentarias.

Diversión.

Combatir el estrés.

\section{Características del ciclismo bajo techo}

Es individual.

Tienen su propio espacio.

Pueden practicarlo tanto principiantes como avanzados.

Se puede controlar la frecuencia cardiaca.

Hay dominio del impacto osteomuscular.

Es fácil de practicar.

Se suda bastante (pueden perderse hasta dos litros de líquido por clase).

No existe prevención sexual.

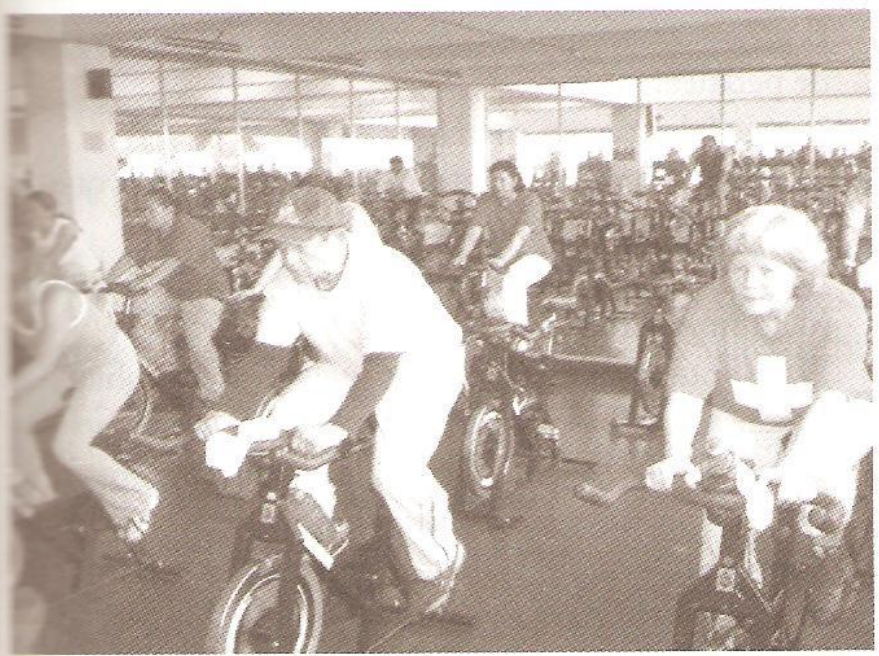

: Édgar Rodríguez.

\section{Qué no debe hacerse en el ciclismo bajo techo}

Por prevención no debería pedalearse a más de 110 rpm (revoluciones por minuto). Lo ideal es $90 \mathrm{rpm}$.

Si se usa una carga muy fuerte, ésta debe moverse mínimo a $60 \mathrm{rpm}$. Sólo para practicantes avanzados, mínimo $40 \mathrm{rpm}$.

- Trabajos demasiado fuertes; precisamente por los problemas del mal manejo de la biomecánica y la técnica en general.

- Usar los brazos y las manos como fuente de fuerza, sólo deben tomarse como apoyo.

No hay coreografía.

No debe haber euforia.
- No es efectivo ponerse de pie por riesgos de lesiones, entre otras, de la articulación femuropatelotibial; además, se suben las pulsaciones.

\section{Indumentaria}

La indumentaria para la práctica del ciclismo bajo techo es muy importante porque debe permitir una buena ventilación, es decir, estar hecha de unos materiales especiales que permitan la absorción del sudor, así como el buen intercambio de aire y, más importante aún, que sea fría, pues cuanto más fría, más calorías se queman.

La ropa interior debería ser de costuras muy delgadas, para evitar el roce que puedan originar las costuras gruesas; y lo ideal sería practicarlo sin ropa interior. Utilizar medias pequeñas para evitar el calor, y calzado de suela dura, porque el de suela blanda puede producir una inflamación del tendón por debajo del pie (fascitis plantar), toalla facial, guantes y agua.

El pantalón corto bicicletero debe estar pegado al cuerpo porque la sudadera o el pantalón pueden enredarse con alguna parte de la bicicleta; lo ideal es que el bicicletero tenga badana, para amortiguar, absorber el sudor y mantener fría la zona de los genitales (en los hombres, $3^{\circ} \mathrm{C}$ más fríos los testículos que el resto del cuerpo). Hay un tipo de ropa especial para ciclismo que se llama CoolMax. Debemos recordar que sudar no es bueno porque el organismo se deshidrata y pueden originarse hongos. Utilizar guantes siempre por higiene, ya que las máquinas son públicas, también previene los callos. En lo posible, que los guantes tengan toalla.

Es peligroso usar el saco en la cintura, ante todo en la mujer, puesto que éste puede enredarse con alguna de las partes de la bicicleta.
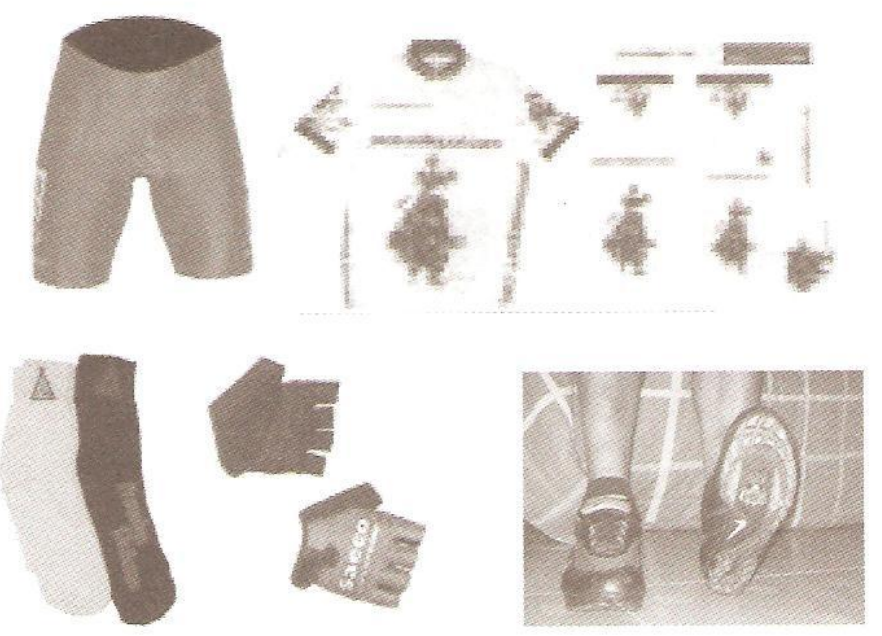

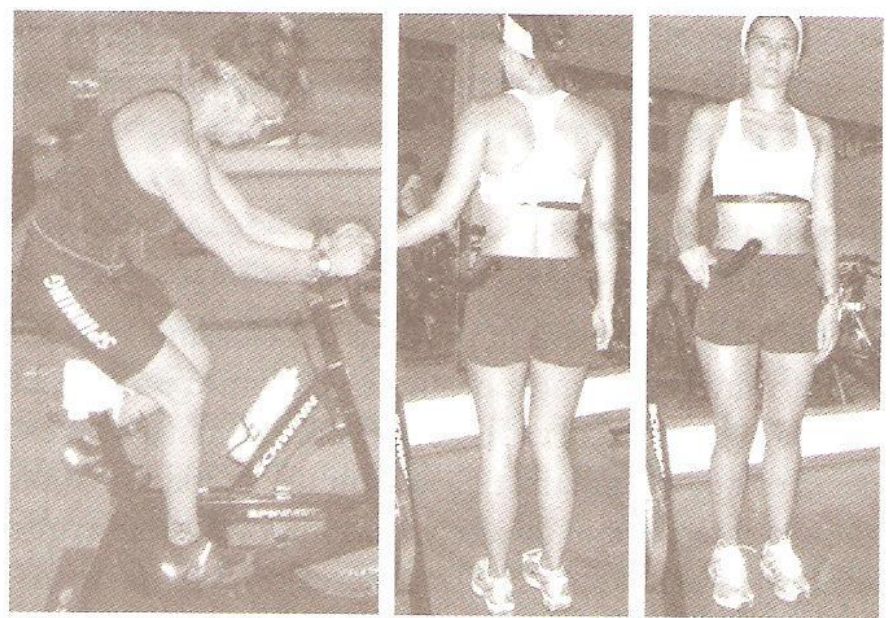

Foto: Édgar Rodríguez.

\section{Seguridad y prevención}

Antes de comenzar una sesión de entrenamiento de ciclismo bajo techo debemos:

- Preguntar si alguien necesita atención especial.

- Preguntar si alguien está por primera vez.

- Mostrar el manejo del freno.

- Enseñar el aumento y la disminución progresiva de la carga.

- Dejar que los participantes se familiaricen con la bicicleta y su funcionamiento.

- Hacer que los participantes comprueben todos los ajustes de la bicicleta.

- Confirmar que el timón, el asiento y su ajuste longitudinal estén bien encajados y ajustados.

- Durante la práctica, recordar a los participantes que cada cual debe trabajar a su ritmo de acuerdo con el principio de la individualidad.

- Recordar a las personas mantener siempre el control y que debe haber siempre resistencia sobre el volante.

- Si un participante tiene problemas, baje de la bicicleta y ayúdelo inmediatamente.

\section{Conocimiento de la bicicleta}

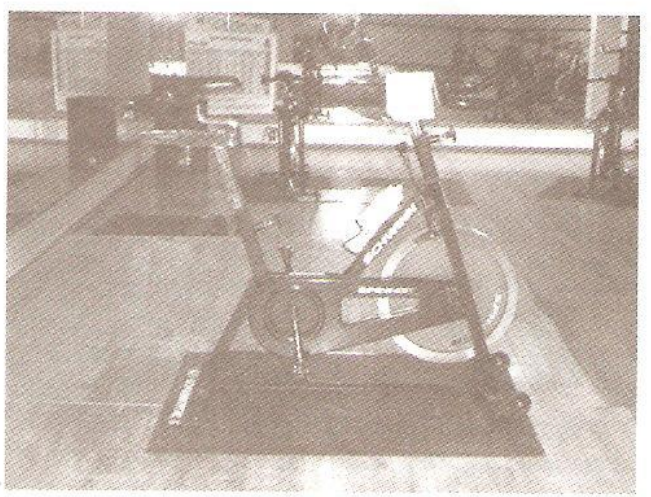

Foto: Édgar Rodríguez.

\section{La bicicleta y sus partes}

- Debe ser pesada.

- Debe tener unas patas con la posibilidad de adaptarse al piso.

- Debe tener una estructura fuerte, es decir, de tráfico pesado. La mejor maquinaria de tráfico pesado es la Startrack. La maquinaria de tráfico liviano mueve máximo 5 personas por día, mientras que la de tráfico pesado, entre 3,5 millones y 5,5 millones de usuarios al año.

- El volante (o rueda metálica) debe ser pesado para que genere inercia, y sólo se usa en bicicletas de Spinning ${ }^{\odot}$. Pesa aproximadamente 17,5 kilos.

- El centro o eje es la parte más importante, se daña con frecuencia y es allí donde se concentra el mayor peso. El eje va unido a las bielas, que lo unen con el pedal. Unidos al eje también van el plato, la cadena y el piñón. El piñón es fijo, y se detiene cuando se deja de pedalear.

- Los pedales tienen correa y calapié.

- El sillín y el timón se ajustan con unas perillas que en su parte final tienen unos tornillos.

- La perilla de la resistencia aprieta y afloja el volante (columpio y Káiser)

- El volante nunca debe estar suelto, las almohadillas deben tocar un poquito el volante. Cuando no hay carga sobre el volante, la rodilla se mueve o rota mucho y se puede ocasionar una lesión.

- Es preferible que el sillín esté construido con un hueco en la mitad para evitar la presión en los genitales.

- La bicicleta también tiene un timón.

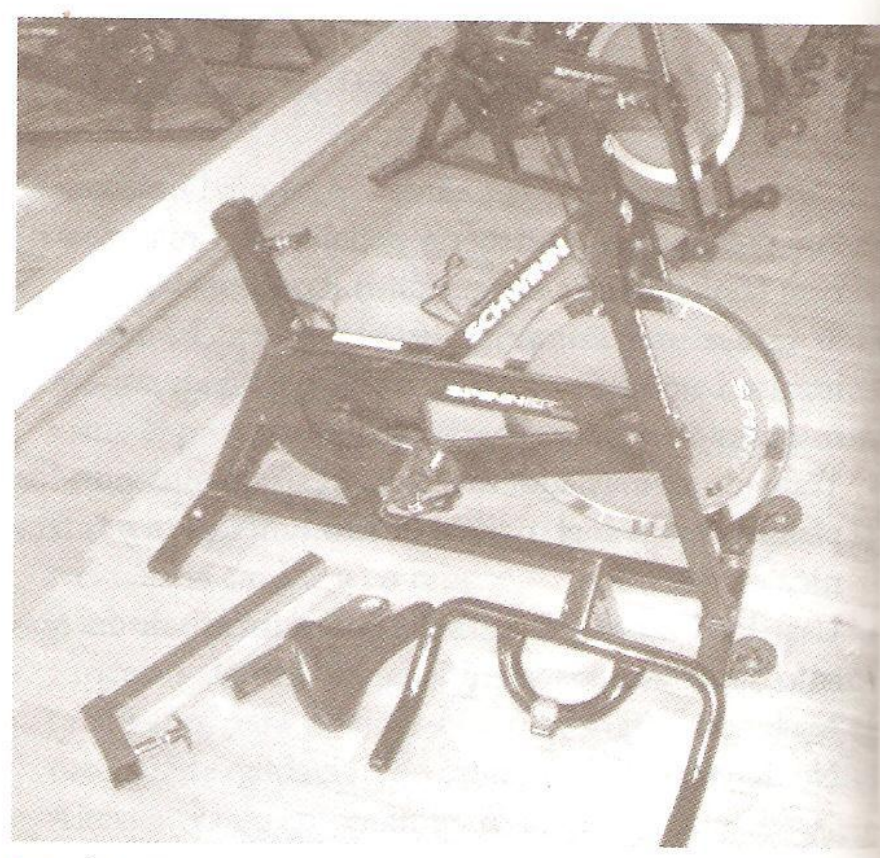

Foto: Édgar Rodríguez. 


\section{Ajustes de la bicicleta}

El instructor debe estar de pie preferiblemente al lado inquierdo de la bicicleta y el usuario al lado derecho de esta, para simular así la imagen de un espejo y dar las siguientes indicaciones:

\section{Estabilidad de la bicicleta}

Hay que regular los estabilizadores, que por lo general son tornillos debajo de cada pata de la bicicleta.

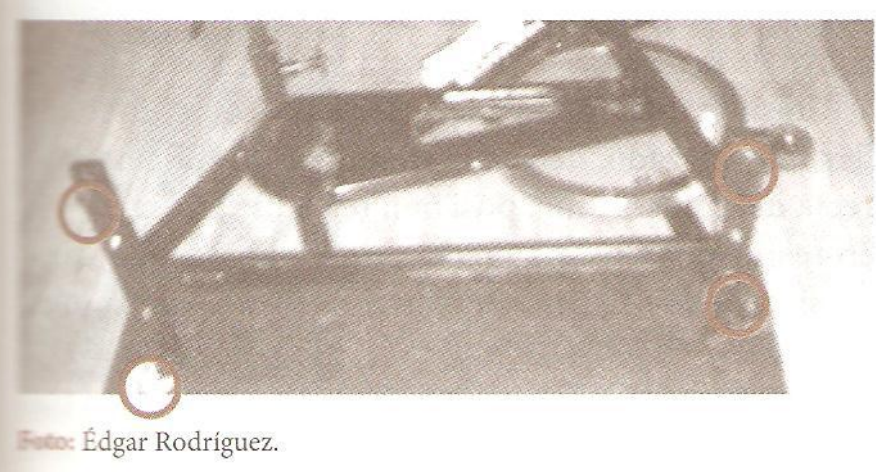

Atura del sillin

De pie al lado de la bicicleta sobre el piso, ubicar dos dedos de la mano bajo la cresta ilíaca. Éste es un ajuste proximal. Corroboramos este ajuste subiendo a la bicicleta acaballándonos, a fin de prevenir daños en los Iigamentos colaterales, que son causados por la subida al estilo "cartero", debido a que todo el peso del cuerpo está apoyado sobre una de las articulaciones femuropatelotibiales, y al girar el cuerpo causa un estrés o impacto articular demasiado grande. Se usa el pedal que esté abajo como un escalón para sentarse bien centrado sobre la parte ancha del sillín, se pone el talón sobre el eje del pedal y la pierna debe quedar totalmente extendida con el pie paralelo al piso; luego introducimos el mismo pie en el calapié, de manera que la articulación metatarsofalángica quede apoyada sobre la base del pedal. En este momento, si la altura del sillín es la correcta, la rodilla tendrá aproximadamente un ángulo de $5^{\circ} \mathrm{con}$ respecto de la vertical.
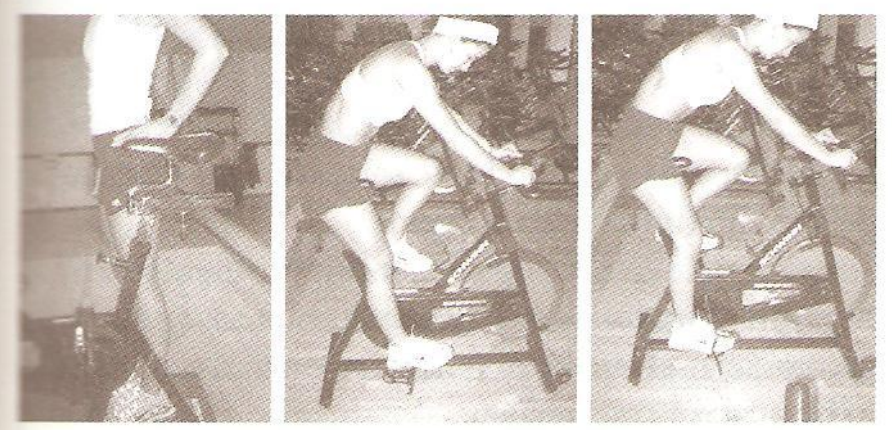

Foto: Édgar Rodríguez.

\section{Ajuste longitudinal del sillin}

Para mover el sillín hacia delante o hacia atrás, sentado en la bicicleta sobre la parte ancha del sillín, ponga el pedal derecho adelante y la biela y el pie paralelos al piso (posiciones 3 y 9 del reloj). Apoye la articulación metatarsofalángica sobre el eje del pedal y revise que la rodilla no sobrepase la punta del pie. La pierna medial debe estar en un ángulo de $90^{\circ}$, la rodilla de adelante forma un eje perpendicular con el piso.

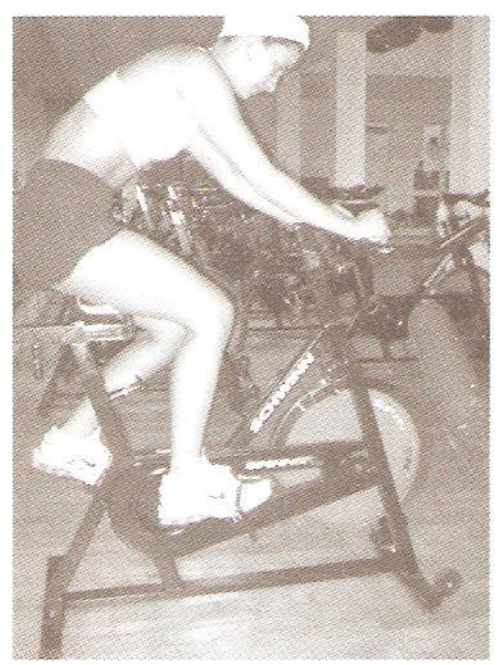

Foto: Édgar Rodríguez.

\section{Ajuste del manubrio}

Debe estar a la misma altura del sillín o más alto, para no causar demasiado estrés en la zona lumbar; en el salón de Spinning no hay viento, por lo cual no necesitamos posiciones aerodinámicas. Lo anterior se aplica a principiantes, mientras que los ciclistas avanzados o profesionales pueden usarlo más abajo.

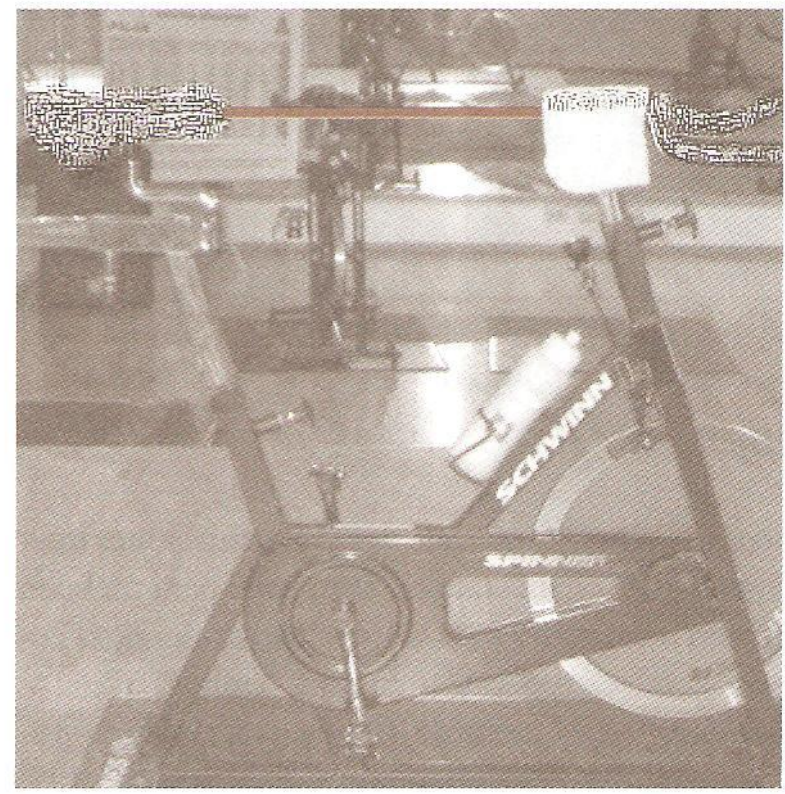

Foto: Édgar Rodríguez. 


\section{Postura sobre la bicicleta}

Sobre la bicicleta los glúteos deben ir bien apoyados en la parte ancha del sillín, las manos sobre el timón en la posición deseada, los codos flexionados, los hombros relajados. No utilizamos para nada la fuerza de los brazos. La espalda debe estar en una inclinación entre 45 y $60^{\circ}$ cuando las manos están sobre el manubrio, ya que pedalear erguido y sentado aumenta la frecuencia cardiaca y el peso del tren inferior está concentrado casi en su totalidad sobre el cóccix. El abdomen debe estar suelto y relajado para tener una mejor captación de oxígeno, las caderas no deben oscilar de lado a lado y la mirada debe ir al frente.

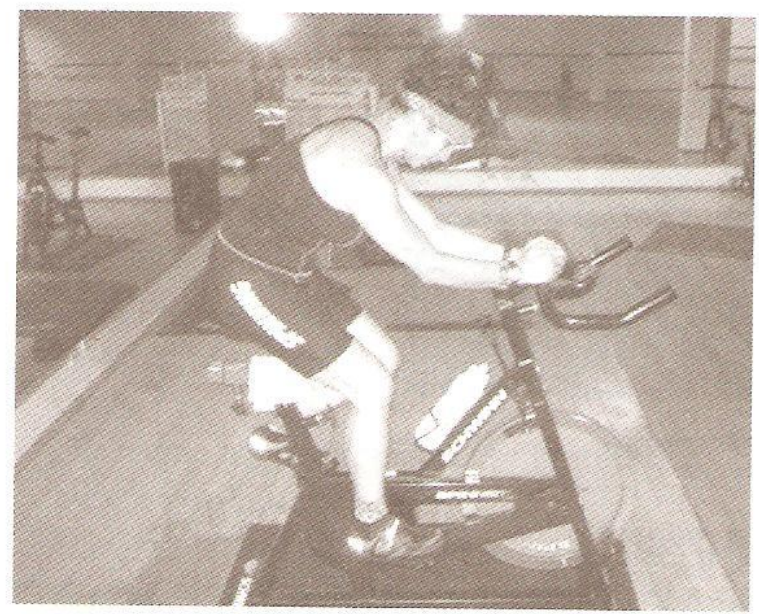

58
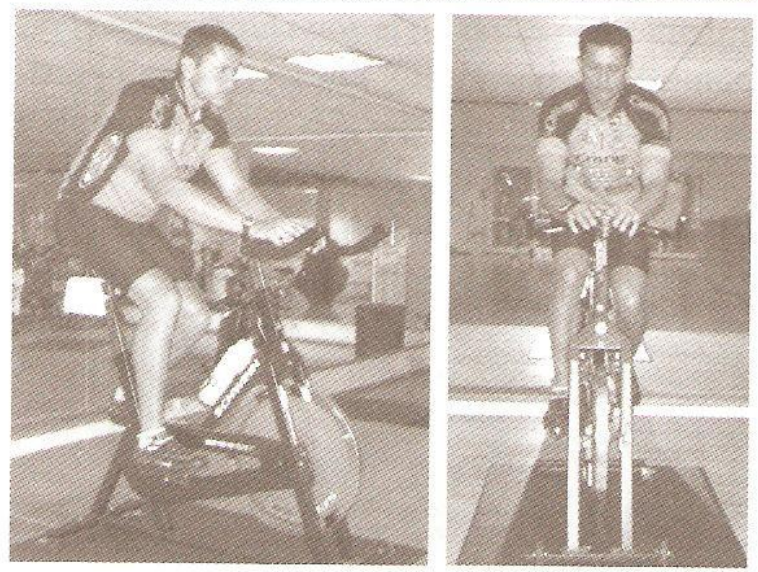

Foto: Édgar Rodríguez.

\section{Trabajo del tronco}

El tronco es el punto de anclaje de las articulaciones inferiores y su acción estabilizadora es esencial para un buen rendimiento muscular y para evitar alteraciones de la columna vertebral, en especial en la zona lumbosacra.

Para conseguir esa estabilidad es esencial una posición correcta del sillín. Una altura excesiva del sillín desequilibra la pelvis en cada golpe de pedal y produce hiperextensión de los músculos lumbares y torsión de la columna lumbosacra.

Un sillín demasiado bajo puede causar, paradójicamente, una lumbalgia de esfuerzo, debido a que la extremidad inferior no encuentra espacio suficiente para extenderse.

Un sillín demasiado retrasado puede causar una hipercifosis de la columna lumbosacra con excesiva tensión del aparato musculotendinoso dorsal. Lo mismo ocurre si la punta del sillín se sobreeleva respecto al apoyo de la pelvis.

Un sillín demasiado adelantado, así como un manillar muy elevado, determinan una postura demasiado recta del tronco y una posición relajante; sin embargo, en realidad la postura erecta origina una mayor compresión de los discos intervertebrales en la zona lumbosacra.

El flujo nutritivo se efectúa en su mayor parte a través del cuerpo vertebral, y esta compresión excesiva dañaría el mecanismo fisiológico de bombeo de nutrientes, lo cual provocaría acumulación de ácido láctico, con estimulación química de las terminaciones nerviosas, dolor y degeneración precoz de los discos intervertebrales.

Todo esto se evita con una posición correcta, lo cual garantiza una acción de bombeo óptimo producido por las cargas submáximas y alternas de trabajo, aumenta el flujo hemático local, aporta nutrientes y elimina metabolitos ácidos. Así pues, el estímulo mecánico normal es indispensable para la vida del músculo y las estructuras pasivas. Con frecuencia, ciclistas con hernias discales y malformaciones congénitas ven atenuados sus problemas de espalda.

\section{Trabajo del cuello}

Esta zona tiene movimientos de propulsión en la fase de pedaleo de pie, y durante el pedaleo sentado la flexoextensión de la columna y el balanceo de la nuca y la cabeza producen energía cinética del segmento. Todas estas acciones pueden compararse con las del delfín. Los ciclistas comúnmente suelen llevar la zona cervical hiperextendida para poder ir sorteando los obstáculos del terreno (mirada fija al suelo).

Esto puede llevarnos al entumecimiento de los músculos cervicales, por lo cual hay que asegurarse de no bloquear el cuello en una posición fija, cambiándolo de postura con frecuencia. 


\section{Posición de las manos}

\section{Manos en posición 1 o de relajación}

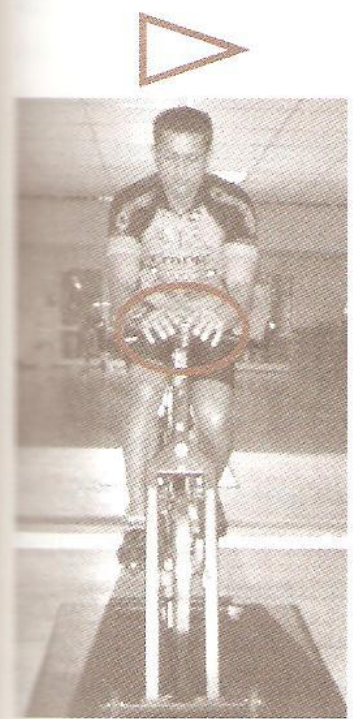

Foto: Édgar Rodríguez.

Sirve para ir sentado en terreno plano y eventualmente para el esfuerzo final (sprints). Se debe ir relajado, las manos se tocan, según la teoría de Johnny G: "al estar las manos en contacto, la energía que hay dentro de cada cual se queda encerrada dentro de sí y el corazón se relaja”.

\section{Manos en posición 2 o de esfuerzo}

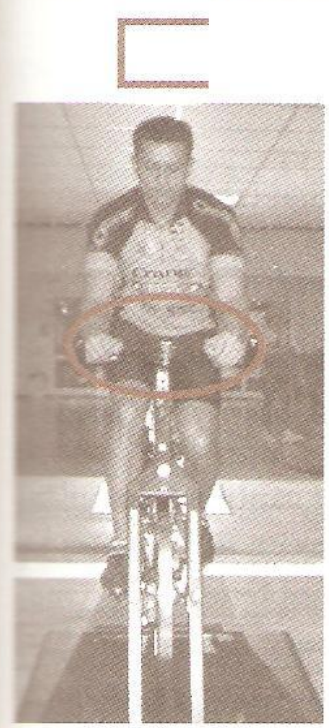

Foto: Édgar Rodríguez.

Sirve para ir sentado en terreno plano, de pie en terreno plano, sentado en terreno de ascenso o de pie en terreno de ascenso. Esta posición amplía la caja torácica y da mayor estabilidad.

\section{Manos en posición 3}

Sólo para ir de pie en terreno de ascenso.

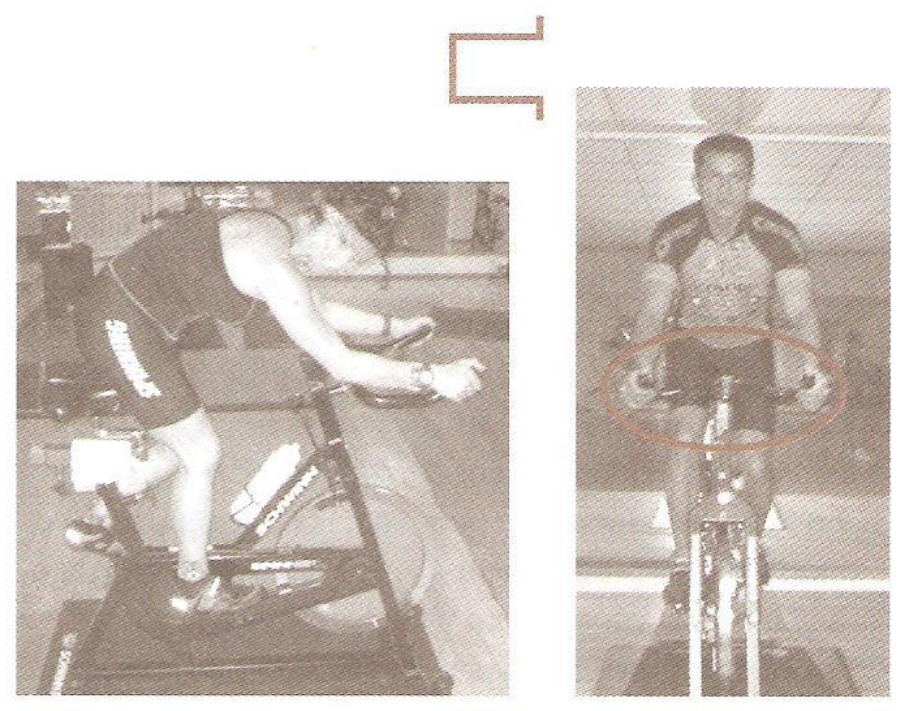

Foto: Édgar Rodríguez.

\section{Técnica de pedaleo}

En la técnica de pedaleo tendremos en cuenta, como primera medida, el tipo de calzado a usar. Los calapiés se usan para efectuar un correcto pedaleo en redondo, aunque lo ideal es el uso de los sujetadores (clips), porque éstos ubican el pie de la manera correcta sobre el pedal sin permitir que se desplace realizando movimientos inadecuados; además, evitan una presión excesiva sobre el pie, lo cual ocurre con el uso de los calapiés. Las correas de los pedales deben estar apretadas pero sueltas.

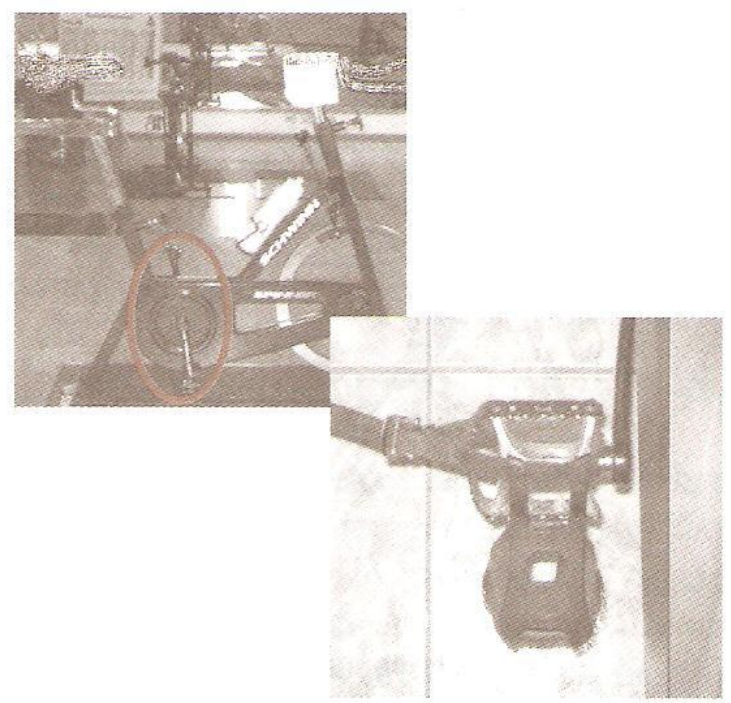

Foto: Édgar Rodríguez.

La técnica de pedaleo consta de cuatro fases y se llama pedaleo en redondo o cuadrante de pedaleo. 


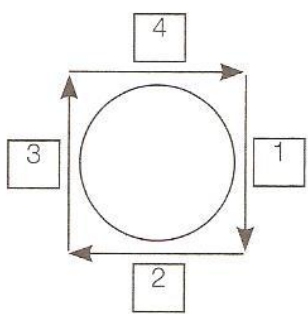

1. Durante la fase 1 empujamos el pedal hacia abajo y el pie va paralelo al piso. Los músculos agonistas son los cuádriceps y los gastrocnemios.

2. En la fase 2 se hala el pedal hacia atrás manteniéndolo paralelo al piso. Los músculos agonistas son los isquiotibiales y los sóleos en su inserción superior.

3. En la fase 3 halamos el pedal hacia arriba tratando de mantener el pie paralelo al piso. Los músculos agonistas son el psoas ilíaco y los isquiotibiales.

4. En la fase 4 empujamos el pedal hacia delante. Aquí utilizamos como músculos agonistas los cuádriceps y los gastrocnemios.

\section{Los grupos musculares afectados}

En la práctica del Health Indoor Cycling se utilizan ante todo los músculos del tren inferior, comenzando por los gastrocnemios, los cuádriceps, los isquiotibiales, el psoas ilíaco y los glúteos; y en menor grado, los músculos del tren superior como los sacrolumbares, los dorsales, el pectoral, los tríceps y los deltoides.

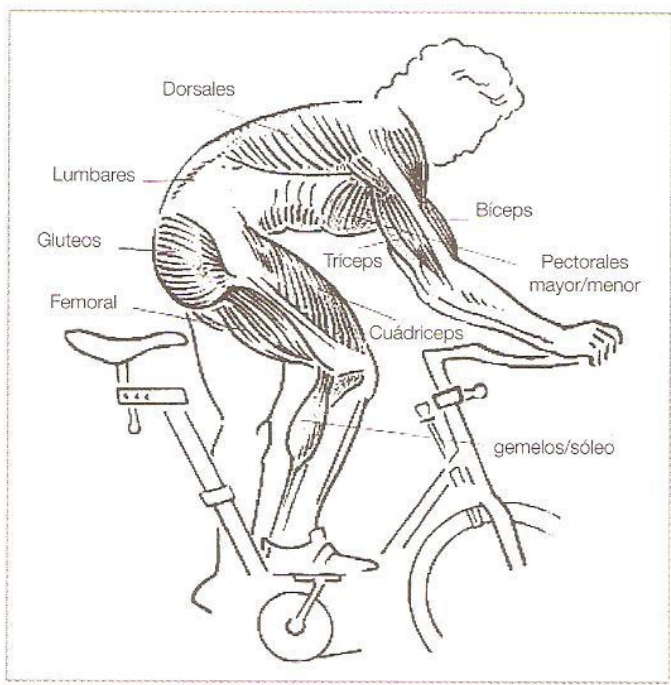

La posición de las rodillas en una técnica de pedaleo correcta debe ser centrada, ni hacia fuera ni hacia dentro; se debe evitar pedalear sobre la punta del pie. La cadencia de pedaleo debe estar regulada de manera que el practicante pueda mantener un ritmo de pedaleo constante.

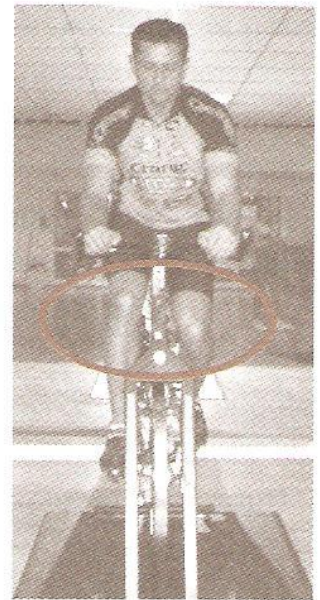

Foto: Édgar Rodríguez.

\section{La cadencia de pedaleo}

Se mide en revoluciones por minuto (rpm), que se cuentan cada vez que la rodilla derecha sube, ya que por lo general el lado derecho tiene el dominio neuromuscular. Se contabiliza cada minuto, o en segundos del 0 al 15 y multiplicando el resultado por 4 . En terreno plano lo ideal es manejar una cadencia de pedaleo de 80 a $110 \mathrm{rpm}$, y en ascenso de 60 a $80 \mathrm{rpm}$ en promedio. Sólo practicantes avanzados pueden ejercitarse hasta $40 \mathrm{rpm}$.

En ascenso también se debe pedalear en redondo.

¿Para que sirve pedalear de pie?

- Mayor uso del peso corporal.

- Se pasa fuerza a la rueda delantera.

- Descanso de estar sentados.

- Como impulso para el esfuerzo final (sprint).

- La frecuencia cardiaca se aumenta.

- Hay cambios en los puntos de apoyo.

\section{El manejo de la frecuencia cardiaca}

La frecuencia cardiaca máxima es la cantidad de pulsaciones máximas del corazón medidas en un minuto. La frecuencia cardiaca máxima puede obtenerse por medio de una prueba directa o una prueba indirecta.

Una de las pruebas indirectas más usadas es la de Martti Joseph Karvonen (Karvonen, www.epi.umn.edu. co), fisiólogo finlandés que realizó investigaciones durante 60 años en la población estadounidense y llegó a la conclusión de que para conocer la frecuencia cardiaca máxima teórica de una persona hay que restarle su edad a 220. Según datos más actualizados, entre otros, por la American College of Sports Medicine, esto no seria 
aplicable en el caso de que en una población deterada las mujeres fuesen más altas, de la misma talla más bajas que los hombres, lo cual puede apreciarse te todo en nuestro país. Otras teorías hablan de que el caso de las mujeres se debe utilizar 206, 210 y 226 menos la edad.

En nuestro método utilizaremos un promedio que será de 210 , en el caso de las mujeres, pues, entre otras cosas, estamos trabajando en la mayor parte de los casos con personas semisedentarias o sedentarias

Otra frecuencia importante para nuestro trabajo en a sala de ciclismo bajo techo es la frecuencia cardiaca asal. Ésta es la cantidad de pulsaciones mínima que requiere nuestro organismo para funcionar. La medimos tomando durante cinco días seguidos las pulsaciones al Jespertar sin levantarse de la cama y sin realizar ningún tipo de actividad. Luego eliminamos los resultados mayor y menor, y sumamos los tres restantes y les sacamos el promedio. Otra manera es dejar colocado el monitor de la frecuencia cardiaca durante toda la noche y observarlo al despertar.

Otra medición importante es la frecuencia cardiaca (FC) de reserva, que la averiguamos restando a la frecuencia cardiaca máxima la frecuencia cardiaca en reposo, o sea:

\section{FCmáx. $-\mathrm{FC}$ en reposo $=\mathrm{FC}$ de reserva}

La frecuencia cardiaca de ejercicio la conseguimos por medio de la siguiente ecuación:

\section{$\mathrm{FC}$ de reserva $+\mathrm{FC}$ basal $\times \%$ deseada para el ejercicio}

La frecuencia cardiaca de recuperación la calculamos luego de aplicar un test especial, por ejemplo el test de Harvard o el test del cajón, modificado, y luego de la actividad revisamos en los primeros tres minutos cómo disminuye la FC; el resultado del último minuto será la recuperación del evaluado y su resultado se averigua analizando los percentiles.

La toma de la frecuencia cardiaca en clase es una herramienta muy útil, ya que servirá para poder controlar el entrenamiento que se haya planteado.

La forma de hacer las tomas sería idealmente cada dos minutos, pero esto desmotivaría un poco a los participantes por lo cual el instructor debe estar muy atento de éstos y realizar los controles de la intensidad que crea necesarios. Claro está que lo ideal sería que los alumnos contaran con el monitor de frecuencia cardiaca; esto simplificaría mucho el trabajo. En caso de no tener mo- nitores de frecuencia cardiaca, se le pedirá a los participantes que utilicen el dedo medio y el dedo índice de la mano y se ubiquen las pulsaciones de la arteria carótida externa en el cuello, o las de la vena radial en la muñeca en supinación.
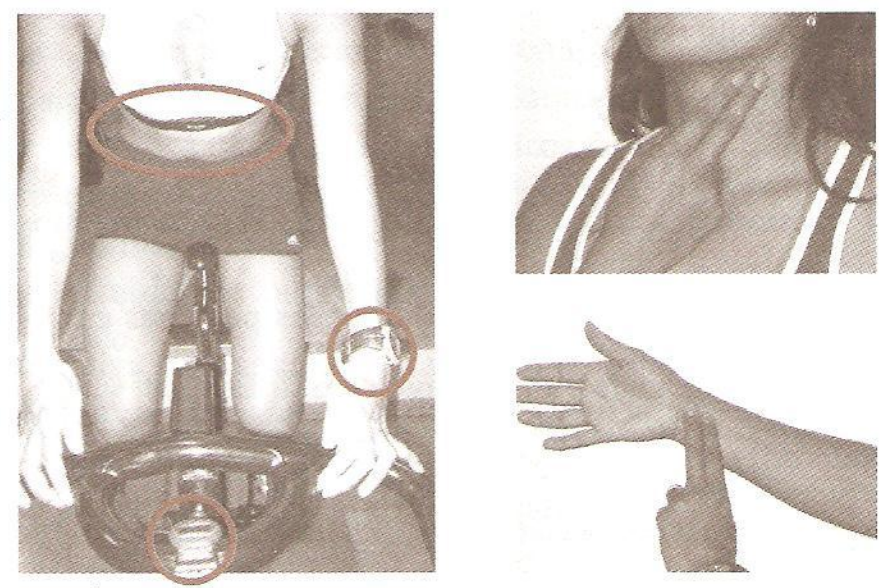

Foto: Édgar Rodríguez.

\section{Terrenos}

En el Health Indoor Cycling diferenciamos dos tipos de terrenos: terreno plano y terreno en ascenso.

El instructor de Health Indoor Cycling debe estar suficientemente capacitado para poder simular y así incentivar a sus alumnos ante los diferentes tipos de terrenos en la sesión de entrenamiento. Por este motivo, el programa Health Indoor Cycling incluye en una de sus fases la práctica en terreno real, con lo cual se busca que los futuros instructores tengan una verdadera experiencia sobre los diferentes terrenos y así puedan transmitirla a sus alumnos.

Como podrá observarse, en los terrenos enunciados no hay terreno de descenso, porque en los descensos reales por lo general no hay pedaleo, lo cual implicaría, en una clase de ciclismo bajo techo, dejar los pedales estáticos.

\section{Zonas energéticas y tipos de clases}

Desarrollar una buena base aeróbica debería ser, por motivos de salud y de rendimiento, el principal objetivo para cada uno de los participantes del ciclismo bajo techo; por esta razón se debería de entrenar dentro de cada una de las zonas energéticas propuestas por el HIC, entendiendo la relación directa entre las zonas energéticas, la frecuencia cardiaca y los sistemas energéticos usados.

Las zonas energéticas propuestas por el HIC son las siguientes: 
a) Zona I. También llamada de regeneración; en el que se maneja una frecuencia cardiaca del 50\% al $60 \%$ de la frecuencia cardiaca máxima, FCM. Esta zona servirá para trabajos de:

- Calentamiento

- Rehabilitación

- Recuperación

- Enfriamiento

- Adaptaciones

- Desintoxicación láctica luego de entrenamientos fuertes.

La zona I debe ser utilizada por las personas entrenadas como mínimo una vez a la semana para evitar el sobreentrenamiento. Este tipo de clases son las menos valoradas, a pesar de ser tan importantes por la recuperación y la sobrecompensación que se lleva a cabo en el organismo.

Una clase dentro de esta zona requiere mucha concentración. Se utiliza una carga baja y se evitan al máximo los ascensos y el ponerse de pie sobre los pedales. En este tipo de clases muy probablemente no haya presencia de sudor.

La clase puede tener una duración de 15 a 45 minutos y utilizamos el método continuo extensivo.

En esta zona las clases dictadas se denominarán de la misma manera que la zona energética, teniendo en cuenta:

- Para trabajos en terreno plano sentados con manos en posición 1.

- Tratar de que los participantes visualicen un terreno llano por donde el grupo de ciclistas viaja a una velocidad moderada baja.

- Carga baja.

- Frecuencia cardiaca del 50 al 60\%.

- Revoluciones por minuto ideales: 80 .

- Duración de la clase: de 15 a 45 minutos.

- Para poblaciones de sedentarios la clase debe durar máximo 30 minutos.

- Para practicantes avanzados puede durar hasta 45 minutos.

Ejemplo:

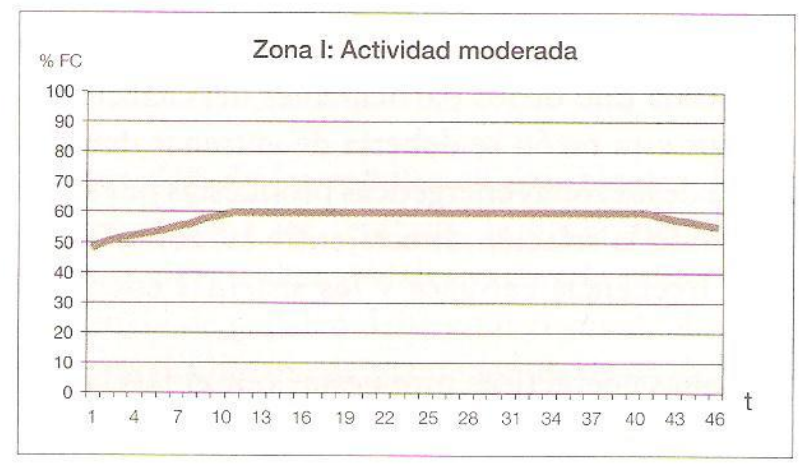

\section{b) Zona II. o zona de betaoxidación}

Frecuencia cardiaca del 60 al 70\% de la FCM. En esta zona se generan los cambios. Según el Colegio Americano de la Salud Deportiva, ACSM, al 70\% del $\mathrm{VO}_{2}$ máximo es donde existe la mayor oxidación de calorías de lípidos, lo cual implica aproximadamente del 60 al 65\% de la FCM. Si durante un entrenamiento para betaoxidación manejamos de una manera constante una FC del $60 \%$, entonces el $70 \%$ de las calorías quemadas totales corresponderán a calorías de lípidos, según el ACSM.

Los métodos de entrenamiento utilizados para las clases en esta zona son el continuo extensivo y el continuo variable, con una duración desde 45 minutos hasta tres horas de trabajo continuo. La sesión de 2 horas en adelante se denominara, según el Health Indoor Cycling, "superclase de betaoxidación".

Las clases para este tipo de entrenamiento podrían trabajarse simulando un terreno plano con cargas moderadas, posición sentado, manos sobre el manubrio en posición 1 ó 2. Se podrá poner a los alumnos de pie con una cadencia de pedaleo suave y por periodos de 15 segundos a un minuto, controlando todo el tiempo la intensidad por medio de la frecuencia cardiaca. La cadencia de pedaleo debe ser de 80 a $100 \mathrm{rpm}$. Las tomas de la FC se harán en espacios de tres a cinco minutos, a menos que los participantes tengan monitores del ritmo cardiaco.

Las ventajas del trabajo en esta zona son las siguientes:

- Mejora la oxidación de las calorías de grasas (bajo aerobios).

- Estabilización del rendimiento.

- Regeneración celular (bajo y alto aerobios).

- Mejoramiento del $\mathrm{VO}_{2}$ máximo.

- Desplaza el umbral anaeróbico.

- Mejora el metabolismo de los glucógenos y aumenta sus depósitos.

- Aumenta la recuperación a cargas de entrenamiento ligeras.

- Permite una mayor flexibilidad en las zonas energéticas.

Ejemplo:

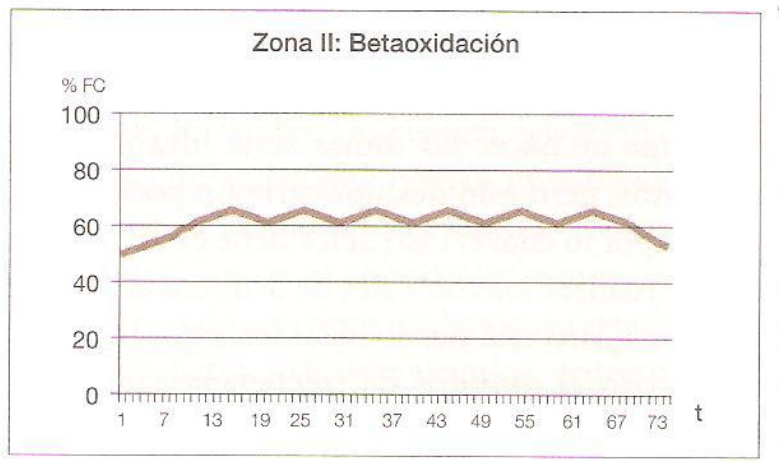




\section{Zona III. Clase saludable}

Se manejará una FC del 60 al $80 \%$ y la clase tendrá una duración de 15 a 90 minutos. Esta clase es ideal para mejorar el volumen cardiaco. Uno de los métodos de entrenamiento utilizados en esta zona energética es el continuo intensivo, que son trabajos en R1, es decir, de 10 a 35 minutos con exigencias submáximas a máximas.

Sus ventajas son:

Mejoramiento en volumen cardiaco, lo cual ayudará para que la frecuencia cardiaca en reposo disminuya. Desplaza el umbral anaeróbico.

Eleva el rendimiento.

Mejora el metabolismo de los glucógenos.

Mejora el $\mathrm{VO}_{2}$ máximo.

En esta zona se trabajaran diferentes tipos de terreno gracias a la variabilidad en la frecuencia cardiaca, por lo cual se manejarán:

Terreno plano, sentado con manos en posición 1 ó 2 y carga moderada.

Terreno plano, de pie con carga moderada y manos en posición 2 .

Terreno en ascenso sentado con manos en posición 2 y carga moderada.

Terreno en ascenso de pie con manos en posición 2 ó 3 y carga moderada.

Estos trabajos se harán también controlando periódicamente la frecuencia cardiaca, ante todo al terminar un terreno difícil, para no sobrepasar el límite de la zona. La cadencia de pedaleo sugerida en el terreno plano es de 80 a $110 \mathrm{rpm}$, y en el terreno en ascenso de 60 a $80 \mathrm{rpm}$. La duración de esta clase puede variar de 15 a 90 minutos, según el método de entrenamiento de a resistencia utilizado.

En esta clase puede visualizarse un terreno plano, colinas, terrenos en ascenso, terrenos extendidos con poca inclinación, todo depende de la creatividad y el diseño de la clase realizados por el instructor. Éste es un ejemplo de clase sugerida por el Health Indoor Cycling.

Ejemplo:

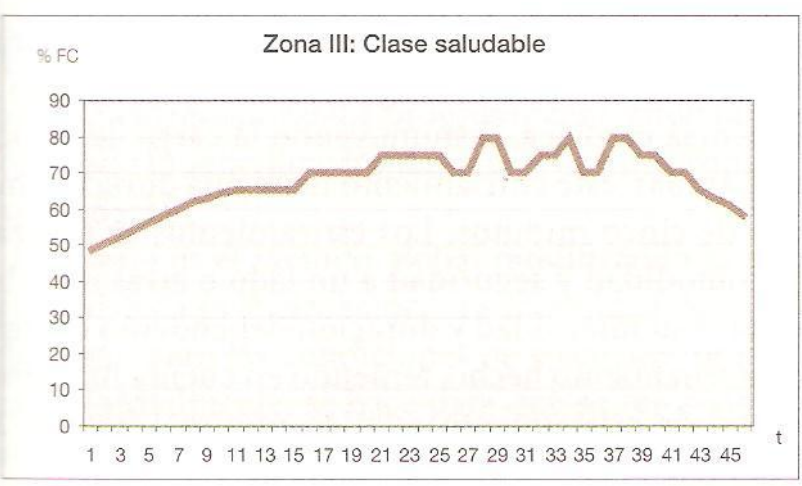

\section{d) Zona IV. Power Hearth}

En esta zona manejamos una frecuencia cardiaca del 75 al $90 \%$ de la frecuencia cardiaca máxima. Utilizamos losl métodos de entrenamiento de la resistencia interválico extensivo e interválico intensivo. Las clases en esta zona son recomendadas para practicantes avanzados, o sea, con un buen periodo de entrenamiento del ciclismo bajo techo. La clase tendrá una duración de 40 minutos, e intervalos de descanso entre picos de cuatro minutos, mientras que cada pico tendrá una duración de 20 a 30 segundos.

También se puede utilizar el método continuo intensivo.

En esta zona puede lograrse un fortalecimiento cardiaco, lo cual es necesario cuando la frecuencia cardiaca en recuperación es deficiente, mejora la capacidad anaeróbica lactásida, aumenta el rendimiento en deportistas y estimula las fibras de contracción rápida.

En esta zona se puede trabajar visualizando un terreno con ascensos muy pronunciados. Este tipo de clase es muy exigente; como recomendación, se debe tener una base de recuperación mínima de 15 minutos y debe haber un buen trabajo de estiramientos al final.

Las posiciones sobre la bicicleta serán: sentado con manos en posición 2, carga fuerte y $40 \mathrm{rpm}$; posición 3 , carga fuerte y $60 \mathrm{rpm}$, visualizando un terreno en ascenso muy pronunciado, donde el instructor puede realizar incluso aceleraciones en ascenso sentado o de pie y saltos en ascenso. Durante la recuperación para mantener la $\mathrm{FC}$ a un $75 \%$ podremos mantener una carga media alta con cadencia de pedaleo alta, de 70 a $80 \mathrm{rpm}$.

Ejemplo:

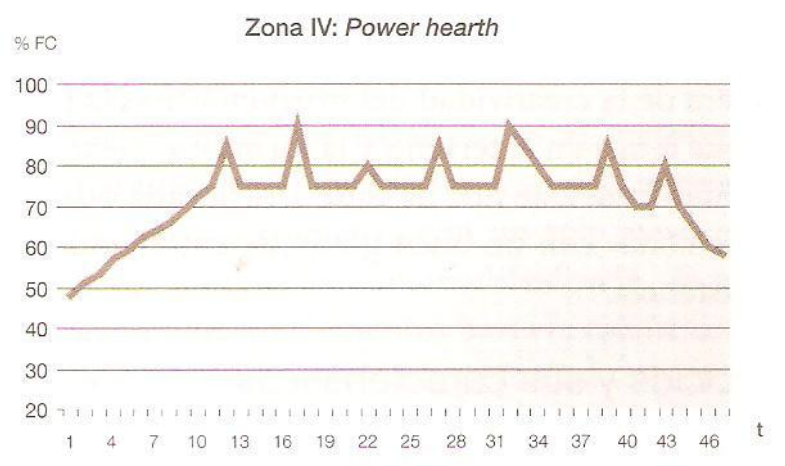

\section{e) Zona V. Extreme}

Se maneja una FC del 90 al 100\%. El método de entrenamiento de la resistencia es el interválico extensivo extremo.

En este método se mejoran los depósitos de fosfato por manejar una frecuencia cardiaca tan excesivamente alta; la recomendación es que todas las condiciones 
del ejercicio estén controladas, por lo cual este entrenamiento se hará sólo con monitoreo autorizado, y se apli$\mathrm{ca}$ a deportistas de alto rendimiento. Este tipo de clase es demasiado peligroso. Es importante tener una base de recuperación de mínimo 15 minutos y un buen estiramiento. Los picos serán de 8 a 10 segundos, mientras los intervalos de descanso serán de 2 a 3 minutos.

Ejemplo:

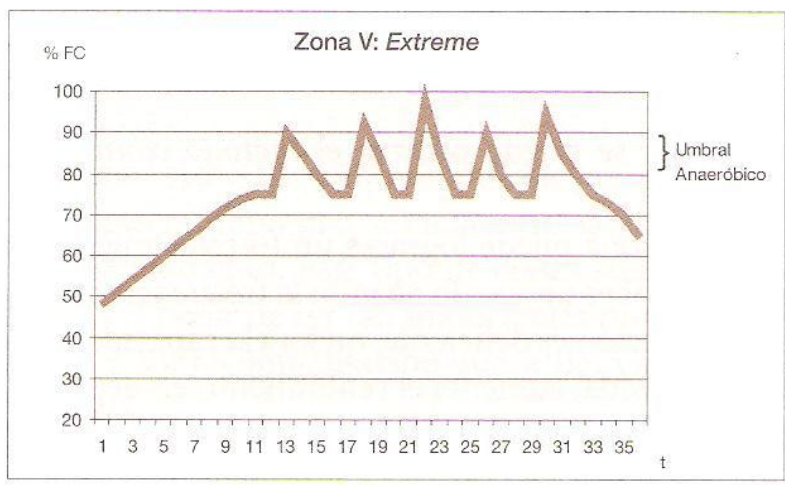

Los anteriores fueron los tipos de clases de acuerdo con la zona energética y el método de entrenamiento de la resistencia usado.

\section{Etapa de competencia}

En el Health Indoor Cycling manejaremos un tipo de clase especial en la cual combinaremos los diferentes terrenos, las zonas energéticas y la incentivación del instructor, la cual consistirá en la simulación de una etapa de ciclismo, por ejemplo una contrarreloj plana o en ascenso, una etapa plana, una etapa de montaña o una etapa combinando el plano con el ascenso, esfuerzo final (sprint) en metas volantes, esfuerzo final en premios de montaña y esfuerzo final en la meta final, todo dependerá de la creatividad del instructor mas la práctica real que tenga en el terreno y la forma en que incentive a sus alumnos. Este tipo de clase será llevada a cabo sólo por personas con un buen grado de entrenamiento de la resistencia.

\section{Ejercicios y sus características}

Los ejercicios básicos que se usan en el Health Indoor Cycling son siete:

1. Sentado en terreno plano

2. De pie en terreno plano

3. Sentado en terreno de ascenso

4. De pie en terreno de ascenso

5. Saltos en los diferentes terrenos

6. Esfuerzo final (sprint) en los diferentes tipos de metas

7. Aceleraciones en terreno plano y de ascenso
Las características de los ejercicios también son siete:

1. La posición sobre la bicicleta en el terreno dado.

2. El terreno, que es lo que el instructor, según su creatividad, está en capacidad de diseñar; claro está que en este momento entra a jugar un papel muy importante la práctica del instructor tanto en el terreno real como en el salón de ciclismo bajo techo.

3. La cadencia de pedaleo, que se mide en rpm, y por lo general se toma en 15 segundos, y el resultado es este dato multiplicado por 4.

4. La zona energética y el tipo de entrenamiento de la resistencia a utilizar.

5. Duración de la sesión de entrenamiento.

6. Posición de las manos sobre el timón.

7. La intensidad expresada en este caso con la frecuencia cardiaca.

\section{Cómo diseñar una clase}

Para el diseño de la clase de ciclismo bajo techo una forma muy práctica es seleccionar la música que se va a usar, lo cual, por lo general, cada instructor hace según su gusto. Luego escoge el método de entrenamiento que va a aplicar durante su clase, y los fusiona sobre el papel. Entonces su creatividad manejará la dinámica de la clase, teniendo en cuenta todos los parámetros técnicos, como la frecuencia cardiaca, la cadencia de pedaleo, etc. Para este tipo de diseño es recomendable que el instructor tenga una persona de apoyo, quien podrá ir dibujando el terreno y anotando los tipos y características que le indique el instructor, como también haciendo sugerencias. La simbología es muy clara y fácil de usar.

La sesión ideal de ciclismo bajo techo constaría de una movilidad articular, 10 minutos de elevación de la temperatura corporal acompañada de un aumento gradual de la frecuencia cardiaca, utilizando para esto la carga sobre el volante, el incremento de la velocidad o ambos para así preparar a los alumnos al trabajo que se realizara según el método de entrenamiento de la resistencia. Aquí puede haber diferentes lapsos. Luego de este trabajo básico, se regresa a la calma bajando la frecuencia cardiaca, disminuyendo la carga, la velocidad o ambas; este enfriamiento tiene una duración mínima de cinco minutos. Los estiramientos se realizan por comodidad y seguridad a un lado o atrás de la bicicleta, y su intensidad y duración dependerán del tipo de entrenamiento hecho, teniendo en cuenta mantener un tipo de estiramiento estático mínimo durante 20 segundos. 
En la sesión ideal el aumento de la carga, sea en tiempo, en velocidad o en resistencia sobre el volante, podrá hacerse por niveles, y en cada nivel se permanecerá aproximadamente durante dos minutos.

\section{Enseñanza del ciclismo bajo techo}

El ser humano lleva muchos años investigando sobre los procesos de enseñanza y de aprendizaje. En el caso específico de los deportes, debemos apoyarnos en lo que nos aportan filósofos, médicos, pedagogos, psicólogos o licenciados en Educación Física, sobre lo que debemos o no hacer. Sin embargo, en la enseñanza del deporte, fundamentalmente en la iniciación, no se plantea de la manera más adecuada en la mayor parte de los casos.

Para los procesos de enseñanza-aprendizaje del ciclismo bajo techo se requiere un método determinado. En este caso, lo más apropiado es utilizar un método en la práctica global, es decir, el instructor presenta el modelo o la actividad en forma completa, o sea, la totalidad de la tarea propuesta. Éste, según Sánchez Bañuelos (1986), se clasifica en global puro, global polarizando la atención, y global modificando la situación real.

Cualquiera de las tres formas es perfectamente ajustable para el HIC. En el método global puro se presenta en su totalidad la ejecución de la tarea propuesta, se utiliza el principio de la progresión. Si la tarea que se va a enseñar es muy simple, no es recomendable utilizarlo como primera opción, en una progresión pedagógica, en tareas complejas.

Igualmente, puede utilizarse el método global polarizando la atención, que desarrolla en su totalidad la tarea propuesta pero solicitando al alumno o la alumna que se fije o ponga atención especial en algún aspecto de la ejecución. Es importante para la enseñanza del HIC porque en la práctica podríamos diseñar una progresión de enseñanza. Así el profesor o la profesora pueden ir desarrollando ejercicios en los cuales el alumno o la alumna vayan polarizando la atención en diferentes aspectos de la tarea motriz. Como norma general, la evolución debe comenzar por el dominio de los aspectos más importantes y más fáciles. Es decir, el profesor-entrenador debe progresar centrando la atención desde lo sencillo y fundamental hasta lo complejo secundario.

El último es el método global modificando la situación real. Ésta es la ejecución en su totalidad de la tarea propuesta, pero las condiciones de ejecución se modifican. Normalmente, se hace para que se vea facilitada; también puede utilizarse para dificultar la situación.
Esta variante puede utilizarse en forma progresiva desde situaciones más sencillas hasta más complejas. Por lo general, forma parte de progresiones de enseñanza. Se aplica con frecuencia en el HIC, en el momento en que se cambian las condiciones de pedaleo, y por ende, las condiciones de la técnica en la bicicleta, para hacer los cambios de velocidades de posición, de intensidades, y de zonas de entrenamiento, lo cual requiere una explicación tanto verbal como visual.

Cuando la tarea se descompone en partes y se enseñan por separado, estamos aplicando el método analítico; Sánchez Bañuelos (1986) cita tres tipos: puro, secuencial y progresivo.

En el HIC estas variantes pueden constituir progresiones de enseñanza por sí mismas, pero la experiencia puede llevarnos a diseñar progresiones que combinen otros tipos, haciendo así más atractivo el proceso de enseñanza-aprendizaje.

En el método analítico puro la tarea se descompone en partes y la ejecución comienza por la parte que el profesor-entrenador considera la más importante. Así sucesivamente, irán practicándose de manera aislada todos sus componentes para, al final, proceder a la síntesis. Esta forma de trabajo es perfectamente desarrollable en el HIC, pues en determinados rangos de edad y en determinados momentos de la preparación del deportista es necesario descomponer la información, lo cual le permitirá una mejor comprensión de lo que tiene por aprender y aplicar.

Cuando se opta por el método analítico secuencial, la tarea se descompone en partes y la ejecución comienza por la primera parte en orden temporal. En algunos casós podría verse como una variante de la primera, sólo que en este caso se determina un orden dado por los tiempos del entrenamiento.

Igualmente, podemos basarnos en el método analítico progresivo, en el cual la tarea se descompone en partes. La práctica comienza con un solo elemento, al cual, una vez dominado, van añadiéndosele, de manera progresiva, nuevos elementos hasta la ejecución total del ejercicio.

En el HIC es posible aplicar uno o varios de los métodos anteriores, bien sea por separado o combinándolos. Esto nos permite enseñar y motivar la práctica del ciclismo bajo techo en grupos poblacionales con diferentes características (edad, género, grado de entrenamiento, condición social, etcétera).

Como lo mencionamos antes, podemos combinar los diferentes métodos, desarrollando así una práctica mixta, la cual trata de sacar lo positivo de cada una. Es 
preciso tener en cuenta que todas las progresiones deben finalizar en forma global. El método mixto comienza siempre con un ejercicio global; después se práctica una parte analítica para volvier a un trabajo global. Queda configurado así omo un método global-analítico-global.

En la práctica 1 del ciclismo bajo techo comúnmente se acude a la enseñanza por instrucción directa. Ésta es la forma tradicional de enseñanza, y está relacionada con el concepto de aprendizaje por imitación o por modelos. El profesor-entrenador transmite los conocimientos que posee al alumno o la alumna para que los aprenda con la mayor exactitud posible. El profesor escoge el fundamento y lo enseña mostrándolo y explicándolo a los alumnos. Este tipo de enseñanza está basado en los siguientes supuestos:

1. El profesor o entrenador es el protagonista del proceso de enseñanza-aprendizaje.

2. Existencia de una solución de rendimiento comprobado y bien definido.

3. Comunicación por parte del profesor de esa solución al alumno.

En este caso, todas las decisiones las toma el profesor: los objetivos, los contenidos, las actividades, la evaluación. El alumno tiene muy pocas opciones de tomar decisiones, y mantiene un papel pasivo. La organización es más formal y resulta más difícil de individualizar.

El estilo más común para el desarrollo del ciclismo bajo techo, HIC, entonces es el comando directo en el cual el profesor emite un estímulo y el alumno debe responder de un modo apropiado y tiene como características:

1. Está basado en la orden del profesor siguiendo el esquema clásico de estímulo-respuesta. El profesor es el experto, es la fuente de conocimiento.

2. El profesor toma todas las decisiones que, en principio, son incuestionables (programación, desarrollo y evaluación).

3. Persigue un modelo conocido.

4. Hay un control estricto de la ejecución del alumno y de su comportamiento.

5. No individualizada, ya que no busca elección de respuestas en el alumno, y todos realizan la misma tarea, el mismo número de repeticiones y a la misma intensidad, de acuerdo con las características de los practicantes.

6. La organización es formal.

Siendo el comando directo el estilo más representativo de la instrucción directa porque desarrolla sus características al máximo, la secuencia de enseñanza es: explicación-demostración, ejecución, evaluación-corrección.

\section{La hidratación}

Ante todo tenemos que recordar que sudar es una forma de eliminar agua, lo cual implica la necesidad de hidratarse para recuperar el agua perdida y evitar deshidratar el organismo. Lo ideal es beber un sorbo de agua o de líquido hidratante cada diez minutos o simplemente antes de sentir la sed. El primer síntoma de deshidratación es precisamente la sed.

- Con el sudor liberamos toxinas, minerales y agua.

- Regula la temperatura corporal.

- Arrastra minerales.

- No elimina grasas. En la mitocondria la grasa entra y se oxida.

El 70\% del cuerpo se compone de agua, y el 75\% del músculo se compone también de agua. El líquido hidratante ideal es el que contenga glucosa y una temperatura de 6 grados centígrados. La hidratación debe realizarse antes, durante y después de la actividad física.

Cuando una persona bebe poca agua, el organismo, como un método de defensa, retiene agua. Recuerde a sus alumnos el uso de las caramañolas, por seguridad y comodidad.

\section{Los estiramientos ${ }^{2}$}

La movilidad articular es la capacidad y la cualidad del deportista para ejecutar movimientos de gran amplitud articular, por sí mismos o bajo la influencia de fuerzas externas.

Se determina por los rangos de elasticidad del músculo y el movimiento articular.

\section{Clasificación}

- General (cómo se estira)

- Específica

- Activa (cómo se entrena)

- Pasiva

También puede clasificarse en relación con la necesidad de desarrollo, y se divides en:

- Absoluta o máxima, o sea, todo el rango de movimiento de la articulación (de dónde a dónde se mueve).

- De trabajo, o sea, cuánto rango de movilidad debe tener la articulación para la actividad.

2 (Siff, 2002: 215-236) 
- Residual es el movimiento articular menos el movimiento de trabajo.

Otra forma de clasificación es la dinámica activa, en la cual la persona estira sola, y la dinámica pasiva en la cual le hacen los estiramientos; estos dos métodos pueden ser lesivos, mientras que la estática activa y la estática pasiva son las más recomendadas.

En el ciclismo bajo techo, como en el ciclismo real, los músculos más implicados durante el trabajo son los del tren inferior por lo cual debe ponerse énfasis en su estiramiento.

Las técnicas de entrenamiento de los estiramien-

tos son:

- Stretching

- Balística

- Facilitación neuromuscular propioceptiva, FNP

El estiramiento:

- Mejora la condición física.

- Prepara para la sesión de entrenamiento.

- Previene lesiones musculares y las disminuye.

- Disminuye el dolor muscular relacionado con el ejercicio.

- Mejora la recuperación.

\section{Referencias}

Contreras Jordán, Onofre R. (1998). Didáctica de la Educación Física, Un enfoque constructivista. Barcelona: Inde.

Fritz, Zintl. (1991). Entrenamiento de la resistencia. Barcelona: Ediciones Martínez Roca.

Johnny, Goldberg. Método de spinning.

López Chicharro, José y Fernández Vaquero, Almudena. (1995). Fisiología del ejercicio. Madrid: Editorial Médica Panamericana.

Páez, Francesco. (2004, 22 de agosto). Memorias del I Seminario Taller de Ciclismo Bajo Techo. Bogotá: Universidad del Rosario.
- Reduce la tensión.

- Aumenta la relajación física y mental.

Por prevención y seguridad los estiramientos deben realizarse abajo de la bicicleta y teniendo en cuenta la cadena cinética.

\section{Seguridad y prevención}

- Valoración física de los participantes.

- No estirar sobre la bicicleta.

- Efectuar todos los ajustes de la bicicleta necesarios y adoptar las posturas adecuadas.

- Buen manejo de la frecuencia cardiaca y las revoluciones por minuto.

- Pedalear siempre con un poco de carga, no dejar el volante libre.

- Hidratar regularmente.

- Usar la caramañola y la toallita facial.

- Usar la indumentaria adecuada.

- Observar al grupo de participantes.

- No entrenar cuando esté dirigiendo la práctica.

- Tomar el curso de primeros auxilios y recuperación cardiopulmonar.
Puche Lacharme, José Daniel. (2004, 22 de agosto) Memorias del I seminario Taller de Ciclismo Bajo Techo. Bogotá: Universidad del Rosario.

República de Colombia. Congreso de la República. Ley 729 de 31 de diciembre de 2001.

Sáenz-López Buñuel, Pedro. (1997). La Educación Física y su didáctica. Sevilla: Wanceulen.

Siff, Mel y Verkhoshansky, Yuri. (1999). Superentrenamiento. 2a. ed. Barcelona: Aidotribo.

Karvonen, Martti Joseph. Activity for a Healthy Life Research Quarterly for Exercise. www.epi.umn.edu. 